\title{
Efficacy of ascorbic acid treatments in the production of green raisins
}

\author{
Prerna Nath $^{1, *}$, S. J. Kale ${ }^{1}$ and A. K. Sharma ${ }^{2}$ \\ ${ }^{1}$ HCP Division, ICAR-Central Institute of Post-Harvest Engineering and Technology, Abohar 152 116, India \\ ${ }^{2}$ ICAR-National Research Centre for Grapes, Pune 412 307, India
}

\begin{abstract}
The quality of raisins is mainly perceived by their colour. Green-coloured raisins are considered as the best quality raisins whereas brown/dark-coloured raisins possess poor quality. Raisin colour is affected by different factors like grape variety, pre-treatments to grape berries, drying method, drying conditions, etc. The present study was conducted to produce greencoloured raisins through two different treatments of ascorbic acid-dipping and spraying. These treatments were applied to Thompson Seedless grapes independently with different doses (100-500 ppm) of ascorbic acid. Results indicated that lesser darkening of raisins was observed when ascorbic acid was sprayed on bunches during drying than the dipping treatment. In all the samples, polyphenol oxidase (PPO) activity decreased with drying duration. Lower PPO content was noted in dipped and sprayed grapes than control. However, application of ascorbic acid influenced the other parameters. The present study revealed that ascorbic acid spray is suitable for retaining green colour in raisins with faster drying. Overall, $200 \mathbf{~ p p m}$ ascorbic acid spray was found appropriate in the production of green raisins.
\end{abstract}

Keywords: Ascorbic acid, dipping and spraying, green raisins, polyphenol oxidase.

RAISINS are dried grapes, commonly known as kishmish, bedana, manuka or dry fruit. They are sweet in taste and their sweet flavour is similar to the grapes from which they are made; however, not all grapes varieties are suitable for making raisins ${ }^{1}$. Raisins are a potential source of various health elements like carbohydrates, folic acid, pantothenic acid, vitamin B6 and minerals (calcium, magnesium, phosphorus, iron, copper, zinc, etc.) which makes them a healthy snack ${ }^{1,2}$. Raisins have a good shelf life of around six months if stored properly. Concentrated sugars, low moisture levels and lower $\mathrm{pH}$ make them a shelf stable food. For prolonged storage, they are refrigerated in tightly sealed plastic bags. Apart from use as a dry fruit item, raisins are also used in large quantities in many sweet preparations, bakery items, farsan (snacks) and desserts (ice-cream and shakes). Raisins are commonly produced by drying grapes. The grapes are either

*For correspondence. (e-mail: prernanath3185@gmail.com) sun-dried or dehydrated mechanically ${ }^{3}$. In India, different varieties of grapes are sun dried to produce raisins. They are usually small, dark and wrinkled in appearance.

Colour is the first notable characteristic of a food and a way to judge its quality. The quality of raisins is also decided on the basis of their colour. Raisins are available in various colours ranging from yellow/golden to black depending upon the method of drying, grape variety, harvesting stage and type of processing. Demand for lightcoloured raisins or green raisins is more compared to darker ones ${ }^{4}$. Consequently, green-coloured raisins fetch higher price in the market and thus provides more profit margin to the producers. Also, the organoleptic quality and nutritional composition of green raisins are on the higher side compared to other commercially available raisins of different colours. The raisin colour is mainly influenced by the type of processing followed during its production.

Raisin production is a major business where grapes are grown. Raisin-producing regions in India are mainly Sangli, Solapur and Nasik districts of Maharashtra, and Bijapur district of Karnataka ${ }^{5}$. However, these raisins are mostly golden or brown in colour. Green-coloured raisins are mainly imported in India and other Asian countries from Afghanistan, where they are produced in traditional mud houses commonly called kishmish khanas. The climatic conditions prevailing in Afghanistan are suitable for retaining green colour in the raisins. The drying conditions during green raisin production include shadedrying, low relative humidity and moderate air temperature (below $40^{\circ} \mathrm{C}$ ). Raisin quality depends on size of the berry, berry colour uniformity, brilliance of berry colour, berry surface condition, skin texture, pulp chemical composition and presence of any foreign matter. However, for retention of green colour in the grape berries during drying there are some basic requirements which include air temperature $25-35^{\circ} \mathrm{C}$, relative humidity $25-35 \%$, mean, moderate air velocity and no direct exposure to sunlight ${ }^{5}$. Besides, green-coloured raisins can also be obtained by employing suitable treatments during grape drying. Sharma et al. ${ }^{6}$ reported the significance of pre-treatments on grape berries for producing lighter-coloured raisins.

One of the major factors influencing raisin colour is the discolouration or browning during drying. Grapes lose their natural green colour and turn brown due to a combi- 
nation of browning reactions during drying, which may be enzymatic and non-enzymatic. Polyphenol oxidase (PPO) is the major causative enzyme for browning in raisins $^{7}$. The reaction is a consequence of the oxidation of phenolic compounds by PPO, which triggers the generation of dark pigments ${ }^{8}$. Also, drying at high temperatures $\left(>40^{\circ} \mathrm{C}\right)$ results in the formation of brown polymers called melanoidins. Studies also indicate that non-enzymatic browning (NEB) is a common reaction observed in products with high sugar content, which further affects the quality of foods by colour changes, loss of sugars and formation of 5-hydroxymethylfurfural ${ }^{9}$. Reducing sugars and ascorbic acid also contribute to browning reactions.

Different chemical treatments for reducing browning reactions in foods have been documented, including application of ascorbic acid in fresh cut fruits and vegetables ${ }^{10-14}$. Ascorbic acid is an antioxidant and also a GRAS (generally recognized as safe) chemical. Use of ascorbic acid and its derivatives as anti-browning agents has been documented in several studies in concentrations ranging from $0.5 \%$ to $4 \%$ (ref. 15 ).

Efficacy of antioxidants such as benzyl adenine and ascorbic acid in reducing the browning of raisins has been studied earlier ${ }^{16,17}$. Raisins produced from Thompson Seedless grapes after treatment with ethyl oleate and ascorbic acid (1000 ppm) solutions showed the lowest browning and increased percentage of green-coloured rai$\operatorname{sins}{ }^{17}$.

However, limited information is available on use of ascorbic acid for retaining the green colour of raisins. Considering the importance of green raisins in terms of economic gains as well as nutritional value, the present study was carried out to evaluate the effect of ascorbic acid application in retaining green colour of raisins.

\section{Materials and methods}

Mature fruits of Vitis vinifera L., commonly known as grapes var. Thompson Seedless (moisture content $82.6 \%$ (wb), total soluble solids $22-23 \%, \mathrm{pH} 3.82$, titrable acidity $4.8 \mathrm{~g} / \mathrm{l}$ ) at the green ripe stage grown in a grape vineyard at Dindori, Nasik, were selected for experiments. Fruits with average diameter at the thickest point in the range $17.5-18.5 \mathrm{~mm}$ were selected for the study. Grapes after harvesting were packed in corrugated boxes lined with a sulphur sheet. They were then brought to ICARCentral Institute of Post-Harvest Engineering and Technology (CIPHET), Abohar within $36 \mathrm{~h}$ of harvesting and stored at a temperature below $4{ }^{\circ} \mathrm{C}$ and used within $24 \mathrm{~h}$. Grapes were taken out of cold storage at least $1 \mathrm{~h}$ prior to experiments, washed and dried with a paper towel.

Grapes were washed with chlorine water followed by separating the damaged and shrivelled berries from the bunches. Each bunch weighing between $100 \mathrm{~g}$ and $150 \mathrm{~g}$ was selected as the sample size. Samples were pretreated by dipping in a beaker containing $500 \mathrm{ml}$ of ethyl oleate $(15 \mathrm{ml} / \mathrm{l})$ and potassium carbonate $(25 \mathrm{~g} / \mathrm{l})$ for $2 \mathrm{~min}$ (based on preliminary trials). The purpose of dipping in this solution is to enhance the rate of drying. Ethyl oleate disturbs the waxy cuticle of grape berries and potassium carbonate acts as an emulsifier. Grapes after pretreatment were rinsed with cold water for approximately $30 \mathrm{~s}$ and used for further study.

\section{Two ascorbic acid treatments applied independently}

Dipping in ascorbic acid solution before drying: Subsequently after ethyl oleate and potassium carbonate treatment, the grapes were dipped in ascorbic acid solution of different concentrations $(100,200,300,400$ and $500 \mathrm{ppm}$ ) for a fixed time of $2 \mathrm{~min}$ (based on preliminary studies). After dipping treatment, the samples were shade-dried. Grapes that were not pretreated with dipping solution served as control.

Spraying of ascorbic acid solution during drying: Samples treated with ethyl oleate and potassium carbonate were shade-dried. Ascorbic acid solution of different strengths $(100,200,300,400$ and 500 ppm) was sprayed on each sample at an interval of $24 \mathrm{~h}$. The spray was applied for $30 \mathrm{~s}$ to each sample from an angle of $45^{\circ}$ at a distance of $1 \mathrm{~m}$, so that all the berries were uniformly coated with ascorbic acid solution. Spraying was done using a sprayer with a nozzle. Spraying treatment was continued till the desired level of moisture content was obtained. Grapes that were not subjected to spraying treatment served as control.

A total of ten treatments of ascorbic acid dip and spray were done independently to the samples. Table 1 gives the treatment codes used in the study.

Samples of grape were shade-dried in a closed ventilated room. During drying, day temperature ranged from $25^{\circ} \mathrm{C}$ to $27^{\circ} \mathrm{C}$ and night temperature from $20^{\circ} \mathrm{C}$ to $22^{\circ} \mathrm{C}$, while relative humidity ranged between $25 \%$ and $35 \%$. Ceiling fan was operated for $8 \mathrm{~h}$ in a day for drying of the samples. The grapes were tied with the help of a string in air for proper air circulation. The dried samples were collected each day to evaluate the changes occurring in colour attributes, moisture content, total phenolic content and PPO activity.

The moisture content of samples was measured using an infrared moisture balance (LCGC Moisture Balance, MAC $50 / \mathrm{NH}, \mathrm{M} / \mathrm{s}$ The Bharat Instruments and Chemicals, Ludhiana) following the standard procedure using AACC ${ }^{18}$ methods.

Colour attributes of raisin samples were determined using Hunter lab colour scale (model no. LX16244, Hunter Associates Laboratory, Virginia, USA) in terms of CIE (Commission Internationale de L'Eclairage) $L^{*}$ 
Table 1. Treatment codes used in the study

\begin{tabular}{|c|c|c|c|c|c|c|}
\hline \multirow[b]{2}{*}{ Ascorbic acid treatment } & \multicolumn{6}{|c|}{ Concentration of ascorbic acid solution (ppm) } \\
\hline & Nil & 100 & 200 & 300 & 400 & 500 \\
\hline Dipping & D0 & D100 & D200 & D300 & D400 & D500 \\
\hline Spraying & S0 & S100 & S200 & S300 & S400 & S500 \\
\hline
\end{tabular}

D, Dipping; S, Spraying.

(lightness and darkness), $a^{*}$ (redness and greenness) and $b^{*}$ (yellowness and blueness). The sensor was standardized with a white tile and a black tile to assess the colour. From each sample, five berries were chosen and the colour values were recorded at two different points. From the $L^{*}, a^{*}$ and $b^{*}$ values, total colour difference $(\Delta E)$ was calculated using eq. (1)

$\Delta E=\sqrt{\left(L_{\text {sample }}^{*}-L_{\text {ref }}^{*}\right)^{2}+\left(a_{\text {sample }}^{*}-a_{\text {ref }}^{*}\right)^{2}+\left(b_{\text {sample }}^{*}-b_{\text {ref }}^{*}\right)^{2}}$,

where 'sample' indicates raisin sample and 'ref' indicates control sample. The $\Delta E$ values obtained were used to determine whether the total colour difference of the raisins was visually obvious from the control samples ${ }^{19}$ as follows

$\Delta E^{*}<1 ; \quad$ Colour difference is not obvious for human eye.

$1<\Delta E^{*}<3$; Minor colour difference that could be appreciated by the human eye depending on the hue.

$\Delta E^{*}>3 ; \quad$ Colour difference is obvious for human eye.

PPO activity in the samples was measured according to the method described by Nath et al. ${ }^{20}$. For this activity, $2 \mathrm{~g}$ of sample was homogenized at $0^{\circ} \mathrm{C}$ in $20 \mathrm{ml}$ of $0.1 \mathrm{M}$ sodium phosphate buffer ( $\mathrm{pH} 7)$. The extract was filtered using a muslin cloth and centrifuged at $0^{\circ} \mathrm{C}$ for $20 \mathrm{~min}$ at $13,109 \mathrm{~g}$. The supernatant was suitably diluted with a known volume of $0.02 \mathrm{M}$ sodium phosphate buffer $(\mathrm{pH}$ 2). Next, $4 \mathrm{ml}$ of $0.1 \mathrm{M}$ phosphate buffer and $0.8 \mathrm{ml}$ of catechol $(0.055 \mathrm{~g}$ dissolved in $100 \mathrm{ml}$ distilled water $)$ were dispensed in four test tubes. One millilitre of distilled water was added in a test tube as sample blank and in the others $1 \mathrm{ml}$ of sample extract was added. The absorbance was measured after 1,2 and 3 min at $410 \mathrm{~nm}$ using UV-Vis spectrophotometer (UV-2550, SHIMADZU, Chandigarh). Three replicates were taken for each sample per treatment.

Browning index in raisins was measured according to the method described by Meydav et al. ${ }^{21}$, with slight modifications, to determine the extent of non-enzymatic browning. The sample extract was centrifuged at $760 \mathrm{~g}$ (Eltek Refrigerated, Mumbai) for $15 \mathrm{~min}$ at room temperature. The supernatant was mixed with ethanol in $1: 1$ dilution (i.e. $10 \mathrm{ml}$ supernatant was mixed with $10 \mathrm{ml}$ ethanol). The mixture was again centrifuged at $760 \mathrm{~g}$ for 10 min. Centrifugation followed absorbance measurement at $420 \mathrm{~nm}$ using UV-Vis spectrophotometer (UV-2550, SHIMADZU, Chandigarh). The results were expressed in terms of absorbance value; higher the absorbance value, higher was the browning in the sample.

All the quality attributes of raisins were measured in triplicate and mean values were determined. Duncan's multiple range test (DMRT) was performed to test the statistical differences in these attributes as affected by different ascorbic acid treatments. SPSS software (version 16.0) was used for DMRT. The significance was accepted at $5 \%$ levels of significance $(P<0.05)$.

Principal component analysis (PCA) was performed to determine the relationships between various quality attributes as well as their association with ascorbic acid treatment. Addin software XLSTAT (version 2014.5.03) was used to perform PCA.

\section{Results and discussion}

Raisin production in India involves dipping the freshly harvested grapes in $2.4 \%$ potassium carbonate and $1.5 \%$ ethyl oleate solution, and subsequent drying under open tier system. However, the resulting raisins have poor colour quality. The colour of raisins is generally yellow, golden-yellow, brown or dark brown. In the present study, known concentrations of ascorbic acid solutions were sprayed on grape berries after dipping in ethyl oleate and potassium carbonate. Ascorbic acid was utilized because of its ability to function as an antibrowning agent. The effect of ascorbic acid treatments on selected quality attributes of raisins evaluated during this study is presented below.

\section{Moisture content}

Results revealed that on the basis of optimum storage moisture content of raisins (20-22\%, wb), drying duration of grapes with different ascorbic acid treatments was 6 days (Table 2). Ascorbic acid treatments significantly 
RESEARCH ARTICLES

Table 2. Effect of ascorbic acid dipping and spraying treatments on moisture content (\%, wet basis (wb)) of raisins

\begin{tabular}{|c|c|c|c|c|c|c|}
\hline Time (days) & D0 & D100 & D200 & D300 & D400 & D500 \\
\hline 0 & $81.14 \pm 6.21 \mathrm{~g}$ & $80.12 \pm 4.52 \mathrm{~g}$ & $81.52 \pm 4.62 \mathrm{~g}$ & $81.28 \pm 7.45 \mathrm{~g}$ & $81.24 \pm 3.21 \mathrm{~g}$ & $80.14 \pm 5.25 \mathrm{~g}$ \\
\hline 1 & $71.85 \pm 2.32 \mathrm{f}$ & $72.14 \pm 4.21 \mathrm{f}$ & $70.14 \pm 3.21 \mathrm{f}$ & $75.58 \pm 2.36 f$ & $73.62 \pm 2.32 \mathrm{f}$ & $71.28 \pm 3.33 f$ \\
\hline 2 & $55.52 \pm 1.32 \mathrm{e}$ & $60.21 \pm 1.25 \mathrm{e}$ & $65.12 \pm 1.36 \mathrm{e}$ & $62.14 \pm 6.32 \mathrm{e}$ & $66.29 \pm 2.21 \mathrm{e}$ & $59.85 \pm 2.31 \mathrm{e}$ \\
\hline 3 & $42.69 \pm 5.62 \mathrm{~d}$ & $51.23 \pm 3.21 \mathrm{~d}$ & $57.18 \pm 5.62 d$ & $53.25 \pm 1.25 \mathrm{~d}$ & $56.54 \pm 5.32 \mathrm{~d}$ & $45.21 \pm 2.31 \mathrm{~d}$ \\
\hline 4 & $35.25 \pm 5.21 \mathrm{c}$ & $45.14 \pm 5.21 \mathrm{c}$ & $46.54 \pm 2.62 c$ & $42.14 \pm 5.26 c$ & $40.41 \pm 4.23 c$ & $37.48 \pm 1.25 \mathrm{c}$ \\
\hline 5 & $28.15 \pm 4.21 b$ & $29.25 \pm 5.32 b$ & $28.74 \pm 1.25 b$ & $30.95 \pm 6.25 b$ & $32.14 \pm 5.14 b$ & $26.58 \pm 1.26 b$ \\
\hline 6 & S0 & $\mathrm{S} 100$ & $\mathrm{~S} 200$ & S300 & S400 & S500 \\
\hline 0 & $81.23 \pm 3.21 \mathrm{~g}$ & $80.12 \pm 4.21 \mathrm{~g}$ & $80.25 \pm 2.36 \mathrm{~g}$ & $81.65 \pm 1.25 \mathrm{~g}$ & $81.11 \pm 9.62 \mathrm{~g}$ & $81.14 \pm 4.21 \mathrm{~g}$ \\
\hline 1 & $72.21 \pm 5.84 f$ & $70.58 \pm 4.32 \mathrm{f}$ & $71.10 \pm 2.12 f$ & $71.24 \pm 3.26 \mathrm{f}$ & $70.14 \pm 1.21 \mathrm{f}$ & $71.14 \pm 4.91 \mathrm{f}$ \\
\hline 2 & $59.25 \pm 1.54 \mathrm{e}$ & $60.20 \pm 3.21 \mathrm{e}$ & $61.16 \pm 1.35 \mathrm{e}$ & $60.58 \pm 5.32 \mathrm{e}$ & $61.62 \pm 5.23 \mathrm{e}$ & $62.29 \pm 5.34 \mathrm{e}$ \\
\hline 3 & $41.10 \pm 2.45 \mathrm{~d}$ & $40.35 \pm 2.35 \mathrm{~d}$ & $42.45 \pm 4.62 \mathrm{~d}$ & $45.20 \pm 4.26 \mathrm{~d}$ & $40.17 \pm 2.32 \mathrm{~d}$ & $51.56 \pm 2.36 \mathrm{~d}$ \\
\hline 4 & $32.15 \pm 6.20 c$ & $31.11 \pm 2.36 \mathrm{c}$ & $31.26 \pm 1.54 \mathrm{c}$ & $30.85 \pm 5.20 \mathrm{c}$ & $32.51 \pm 3.14 \mathrm{c}$ & $43.26 \pm 2.15 c$ \\
\hline 5 & $29.28 \pm 2.21 b$ & $26.84 \pm 1.36 b$ & $27.45 \pm 2.25 b$ & $27.74 \pm 4.36 b$ & $27.20 \pm 2.36 b$ & $32.26 \pm 2.32 b$ \\
\hline
\end{tabular}

Values are mean of triplicate determinations \pm standard deviation. Different letters within the same column are statistically different $(P<0.05)$.

$(P<0.05)$ affected the moisture content of grape berries. Among dipping treatments, minimum moisture content was observed in treatment D500. The moisture content in control (D0) berries after 6 days of drying was higher, $(23.25 \%)$ in comparison to ascorbic acid-treated berries where moisture content ranged from $21.86 \%$ to $20.21 \%$. This implies that dipping in ascorbic acid solution helped in faster removal of moisture during drying.

Similarly, in spraying treatments, significant $(P<0.05)$ decrease in moisture content of berries was observed. The moisture content values decreased from $81.23 \%$ to $25.45 \%$ in S0 treatment after 6 days. Similar trends were observed in other treated samples (S100-S500) also. However, the decrease in moisture content during drying was more for higher concentration levels. The final moisture content of samples sprayed with S100, S200, S300, S400 and S500 ppm concentrations of ascorbic acid was $22.14 \%, 21.45 \%, 20.81 \%, 19.60 \%$ and $19.86 \%$ respectively. On comparing the final moisture content of berries treated with corresponding concentrations of dipping and spraying treatments, it was found that ascorbic acid spray during drying was more effective than the dipping treatments in removing moisture from grape berries.

\section{Colour attributes}

Colour is one of the most important sensory attributes of foods due to its direct influence on consumer acceptability. Studies show that consumers prefer light-coloured raisins due to their associated sensory and nutritional quality ${ }^{4}$. In the present study, the effect of ascorbic acid dipping and spraying treatments on colour attributes of raisin samples was determined (Table 3). Ascorbic acid application as a dip or spray was found suitable in maintaining the green colour of raisins. Both dipping and spraying treatments had significant $(P<0.05)$ impact on final colour values.
On the basis of visual observations, it was observed that spraying treatment was superior to the dipping treatment in terms of retaining the raisin colour.

Lightness $\left(L^{*}\right)$, redness $\left(a^{*}\right)$ and yellowness $\left(b^{*}\right)$ values of samples subjected to dipping treatment ranged from 45.36 to $41.86,20.2$ to 38.02 and 18.98 to 31.72 respectively. Lightness value was highest (44.1) in D500 treatment and lowest in D0 treatment (41.86) on the sixth day of drying. Initially, during drying, no significant $(P<0.05)$ difference was observed between the treatments. Amongst various samples, as the concentration of ascorbic acid increased, simultaneous increase in $L^{*}$ values was also observed; however, the change was nonsignificant $(P<0.05)$. Redness value $\left(a^{*}\right)$ of raisins was also significantly $(P<0.05)$ affected by ascorbic acid treatments. Grncarevic and Lewis ${ }^{22}$ noted that Hunter Lab's $L^{*}$ and $b^{*}$ are the best correlating colour parameters compared to $a^{*}$ for colour quality of raisins. However, in the present study, $a^{*}$ value was given more importance as we were looking for green colour of raisins. In case of dipping treatments, $a^{*}$ values increased during the drying period from day zero to the sixth day. The values were $27.51,23.95,22.14,22.14,23.56$ and 23.14 on the second day of drying in D0, D100, D200, D300, D400 and D500 ppm respectively. Yellowness $\left(b^{*}\right)$ showed a trend similar to lightness, and the values decreased during the drying period amongst all the six treatments. The values in D0 sample were lowest (18.98) initially on day zero and highest (31.72) on the sixth day during drying. Moreover, results also indicated that ascorbic acid concentration of $\geq 200 \mathrm{ppm}$ in dipping treatments was sufficient in maintaining green colour of raisins.

Almost similar trends in observations were recorded in case of spraying treatments, where different concentrations of ascorbic acid were sprayed on grape berries at definite intervals of time. Table 3 shows that $L^{*}, a^{*}$ and 


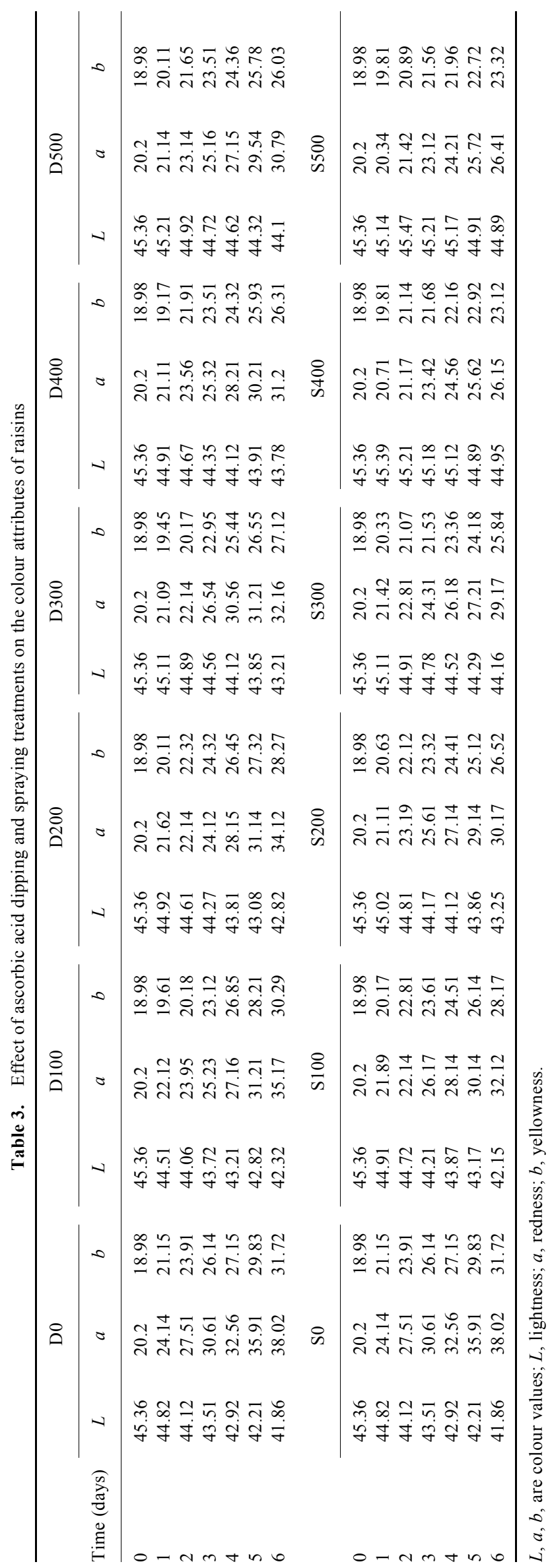


RESEARCH ARTICLES

Table 4. Effect of ascorbic acid dipping and spraying treatments on polyphenol oxidase activity $\left(E U \mathrm{ml}^{-1} \mathrm{~min}^{-1}\right)$ of raisins

\begin{tabular}{|c|c|c|c|c|c|c|}
\hline Time (days) & D0 & D100 & D200 & D300 & D400 & D500 \\
\hline 0 & $86.24 \pm 2.32 \mathrm{~g}$ & $86.24 \pm 2.32 \mathrm{~g}$ & $86.24 \pm 2.32 \mathrm{~g}$ & $86.24 \pm 2.32 \mathrm{~g}$ & $86.24 \pm 2.32 \mathrm{~g}$ & $86.24 \pm 2.32 \mathrm{~g}$ \\
\hline 1 & $68.13 \pm 3.21 \mathrm{f}$ & $63.68 \pm 4.32 \mathrm{f}$ & $60.12 \pm 2.36 f$ & $62.15 \pm 2.52 f$ & $63.40 \pm 2.11 \mathrm{f}$ & $62.32 \pm 5.32 f$ \\
\hline 2 & $51.20 \pm 2.32 \mathrm{e}$ & $51.14 \pm 2.21 \mathrm{e}$ & $48.58 \pm 3.17 \mathrm{e}$ & $51.25 \pm 1.32 \mathrm{e}$ & $52.29 \pm 2.56 \mathrm{e}$ & $50.52 \pm 4.21 \mathrm{e}$ \\
\hline 3 & $40.52 \pm 1.21 \mathrm{~d}$ & $39.75 \pm 6.32 \mathrm{~d}$ & $35.51 \pm 2.58 \mathrm{~d}$ & $35.56 \pm 6.21 \mathrm{~d}$ & $34.15 \pm 4.21 \mathrm{~d}$ & $43.15 \pm 2.32 \mathrm{~d}$ \\
\hline 4 & $31.54 \pm 3.25 \mathrm{c}$ & $25.24 \pm 1.25 \mathrm{c}$ & $22.02 \pm 2.46 \mathrm{c}$ & $25.25 \pm 5.21 \mathrm{c}$ & $23.22 \pm 1.32 \mathrm{c}$ & $32.85 \pm 4.21 \mathrm{c}$ \\
\hline 5 & $22.55 \pm 2.22 b$ & $18.87 \pm 4.21 b$ & $16.25 \pm 1.96 b$ & $15.14 \pm 1.22 b$ & $17.28 \pm 1.42 b$ & $26.58 \pm 1.23 b$ \\
\hline 6 & S0 & $\mathrm{S} 100$ & S200 & S300 & S400 & $\mathrm{S} 500$ \\
\hline 0 & $86.24 \pm 2.32 \mathrm{~g}$ & $86.24 \pm 2.32 \mathrm{~g}$ & $86.24 \pm 2.32 \mathrm{~g}$ & $86.24 \pm 2.32 \mathrm{~g}$ & $86.24 \pm 2.32 \mathrm{~g}$ & $86.24 \pm 2.32 \mathrm{~g}$ \\
\hline 1 & $62.12 \pm 5.32 \mathrm{f}$ & $53.68 \pm 2.35 f$ & $50.14 \pm 2.36 f$ & $52.15 \pm 2.11 \mathrm{f}$ & $53.40 \pm 5.62 \mathrm{f}$ & $52.14 \pm 2.32 \mathrm{f}$ \\
\hline 2 & $45.22 \pm 4.32 \mathrm{e}$ & $40.14 \pm 6.33 \mathrm{e}$ & $38.58 \pm 5.22 \mathrm{e}$ & $41.25 \pm 2.36 \mathrm{e}$ & $42.19 \pm 4.32 \mathrm{e}$ & $40.15 \pm 1.23 \mathrm{e}$ \\
\hline 3 & $30.52 \pm 2.36 \mathrm{~d}$ & $29.85 \pm 1.22 \mathrm{~d}$ & $25.51 \pm 3.61 d$ & $26.56 \pm 1.33 \mathrm{~d}$ & $24.89 \pm 2.15 d$ & $23.54 \pm 2.51 \mathrm{~d}$ \\
\hline 4 & $23.54 \pm 1.36 \mathrm{c}$ & $15.24 \pm 1.52 \mathrm{c}$ & $12.02 \pm 2.36 \mathrm{c}$ & $13.25 \pm 5.21 \mathrm{c}$ & $13.22 \pm 2.13 \mathrm{c}$ & $12.56 \pm 1.42 \mathrm{c}$ \\
\hline 6 & $14.21 \pm 1.55 \mathrm{a}$ & $3.80 \pm 0.62 \mathrm{a}$ & $3.20 \pm 0.95 a$ & $4.25 \pm 1.63 \mathrm{a}$ & $4.50 \pm 1.85 \mathrm{a}$ & $3.05 \pm 1.06 \mathrm{a}$ \\
\hline
\end{tabular}

Values are mean of triplicate determinations \pm standard deviation. Different letters within the same column are statistically different $(P<0.05)$.

$b^{*}$ values are significantly $(P<0.05)$ affected by spraying treatment. The visual colour showed slight change from green to light green, but the colour quality was appreciable. The colour values in terms of lightness, redness and yellowness ranged from 45.36 to $41.86,38.02$ to 20.2 and 31.72 to 18.98 respectively. On comparing with dipping treatments, it was seen that raisin samples treated with spraying treatment retained more green colour. Lightness in S0 samples decreased significantly $(P<0.05)$ from 45.36 on day zero to 41.86 on the sixth day of drying. Decrease in $L^{*}$ value implies darker coloured sample; however, ascorbic acid spray resulted in brighter samples. Per cent decrease in lightness was less in case of spraying-treated samples. Also, increase in ascorbic acid concentration resulted in significant $(P<0.05)$ decrease in $L^{*}$ values of all the samples. $L^{*}$ value on the sixth day of drying in decreasing order was observed as $41.86>$ $42.15>43.25>44.16>44.95>44.89$ in S0, S100, S200, $\mathrm{S} 300, \mathrm{~S} 400$ and $\mathrm{S} 500 \mathrm{ppm}$ respectively.

Generally, $a^{*}$ value is related to the degree of redness in the samples or the level of browning due to drying or processing. With an increase in ascorbic acid concentration in spraying treatments, the level of redness in the samples decreased significantly $(P<0.05)$ from S0 to S500 treatments. However, $a^{*}$ value increased significantly $(P>0.05)$ in the respective treatments. The results were found to be similar to the $b^{*}$ values. Lower $b^{*}$ value was observed in ascorbic acid-sprayed samples than in S0 sample. The $b^{*}$ value in S0 sample was 18.98 on day zero and increased to 31.72 on the sixth day of drying. Whereas with subsequent drying duration, the per cent increase in $b^{*}$ values was less in ascorbic acid-sprayed samples than S0 sample; however, the difference observed in both the cases was significant $(P>0.05)$. With increase in ascorbic acid concentration from S100 to S500, significant decrease $(P<0.05)$ in $b^{*}$ values was recorded.

\section{Polyphenol oxidase activity}

PPO is a group of enzymes that catalyse the oxidation of phenolic compounds to produce a brown colour in exposed and disrupted tissues of plants. Application of ascorbic acid had an impact on PPO activity. Lower PPO activity was noted in ascorbic acid-treated grape berries than D0 and S0 treatments (Table 4). Decrease in PPO activity was observed with increasing drying time in each treatment. Initial PPO activity under dipping treatments was recorded as $86.241 \mathrm{EU} \mathrm{ml}^{-1} \mathrm{~min}^{-1}$; it decreased with the drying period. PPO activity in dipped samples ranged from 86.210 to $10.2 \mathrm{EU} \mathrm{ml}^{-1} \mathrm{~min}^{-1}$. Lower PPO activity was recorded in D200, D300 and D400 with values of $10.2,10.25$ and $11.145 \mathrm{EU} \mathrm{ml}^{-1} \mathrm{~min}^{-1}$ respectively, whereas higher activity was observed in D500 (13.545 EU ml $\mathrm{min}^{-1}$ ) on the sixth day of drying. Minimum activity, i.e. $10.200 \mathrm{EU} \mathrm{ml}^{-1} \mathrm{~min}^{-1}$ was also observed on the sixth day of drying in grapes treated with D200 of ascorbic acid (Table 3), whereas maximum activity (15.210 EU ml $\mathrm{min}^{-1}$ ) was recorded for D0.

Similar observations were made in grape berries treated with ascorbic acid spray during drying. The enzyme activity ranged from 86.241 to $3.050 \mathrm{EU} \mathrm{ml}^{-1} \mathrm{~min}^{-1}$. Lowest activity $\left(3.050 \mathrm{EU} \mathrm{ml}^{-1} \mathrm{~min}^{-1}\right.$ ) was observed in S500 treatment and maximum activity $\left(14.210 \mathrm{EU} \mathrm{ml}^{-}\right.$ ${ }^{1} \mathrm{~min}^{-1}$ ) was noticed in S0 treatment. The decrease in PPO activity with drying time might be due to increasing sugar content with subsequent moisture loss. Our results are in agreement with those of Zheng et al. ${ }^{23}$ and Yaar et $a .^{24}$; who found that ascorbic acid was the most 
RESEARCH ARTICLES

Table 5. Effect of ascorbic acid dipping and spraying treatments on browning index of raisins

\begin{tabular}{|c|c|c|c|c|c|c|}
\hline Time (days) & D0 & D100 & D200 & D300 & D400 & D500 \\
\hline 0 & $0.21 \pm 0.2 \mathrm{a}$ & $0.21 \pm 0.2 \mathrm{a}$ & $0.20 \pm 0.2 \mathrm{a}$ & $0.20 \pm 0.2 \mathrm{a}$ & $0.20 \pm 0.2 \mathrm{a}$ & $0.20 \pm 0.2 \mathrm{a}$ \\
\hline 1 & $0.35 \pm 0.3 b$ & $0.30 \pm 0.1 b$ & $0.39 \pm 0.2 b$ & $0.39 \pm 0.3 b$ & $0.36 \pm 0.1 b$ & $0.33 \pm 0.6 b$ \\
\hline 2 & $0.56 \pm 0.1 c$ & $0.41 \pm 0.3 c$ & $0.45 \pm 0.3 c$ & $0.45 \pm 0.2 c$ & $0.51 \pm 0.2 \mathrm{c}$ & $0.45 \pm 0.2 \mathrm{c}$ \\
\hline 3 & $0.67 \pm 0.2 \mathrm{~d}$ & $0.51 \pm 0.3 \mathrm{~d}$ & $0.56 \pm 0.2 \mathrm{~d}$ & $0.59 \pm 0.1 \mathrm{~d}$ & $0.63 \pm 0.3 d$ & $0.63 \pm 0.5 \mathrm{~d}$ \\
\hline 4 & $0.81 \pm 0.1 \mathrm{e}$ & $0.60 \pm 0.1 \mathrm{e}$ & $0.63 \pm 0.1 \mathrm{e}$ & $0.74 \pm 0.6 \mathrm{e}$ & $0.79 \pm 0.3 \mathrm{e}$ & $0.80 \pm 0.3 \mathrm{e}$ \\
\hline 5 & $0.91 \pm 0.3 \mathrm{f}$ & $0.73 \pm 0.2 f$ & $0.74 \pm 0.6 f$ & $0.81 \pm 0.2 \mathrm{f}$ & $0.96 \pm 0.6 \mathrm{f}$ & $0.95 \pm 0.6 \mathrm{f}$ \\
\hline 6 & S0 & $\mathrm{S} 100$ & S200 & S300 & S400 & S500 \\
\hline 0 & $0.20 \pm 0.2 \mathrm{a}$ & $0.21 \pm 0.2 \mathrm{a}$ & $0.20 \pm 0.1 \mathrm{a}$ & $0.20 \pm 0.2 \mathrm{a}$ & $0.20 \pm 0.2 \mathrm{a}$ & $0.20 \pm 0.1 \mathrm{a}$ \\
\hline 1 & $0.32 \pm 0.2 b$ & $0.28 \pm 0.3 b$ & $0.37 \pm 0.2 b$ & $0.36 \pm 0.1 b$ & $0.37 \pm 0.1 b$ & $0.32 \pm 0.2 b$ \\
\hline 2 & $0.51 \pm 0.1 \mathrm{c}$ & $0.38 \pm 0.1 \mathrm{c}$ & $0.48 \pm 0.3 c$ & $0.45 \pm 0.3 c$ & $0.47 \pm 0.3 c$ & $0.43 \pm 0.3 c$ \\
\hline 3 & $0.62 \pm 0.3 \mathrm{~d}$ & $0.41 \pm 0.2 \mathrm{~d}$ & $0.52 \pm 0.5 \mathrm{~d}$ & $0.56 \pm 0.4 d$ & $0.60 \pm 0.5 \mathrm{~d}$ & $0.61 \pm 0.4 \mathrm{~d}$ \\
\hline 4 & $0.75 \pm 0.2 \mathrm{e}$ & $0.65 \pm 0.3 \mathrm{e}$ & $0.67 \pm 0.6 \mathrm{e}$ & $0.70 \pm 0.5 \mathrm{e}$ & $0.78 \pm 0.6 \mathrm{e}$ & $0.79 \pm 0.6 \mathrm{e}$ \\
\hline 5 & $0.98 \pm 0.1 \mathrm{f}$ & $0.85 \pm 0.1 \mathrm{f}$ & $0.87 \pm 0.6 f$ & $0.82 \pm 0.8 \mathrm{f}$ & $0.93 \pm 0.4 \mathrm{f}$ & $0.92 \pm 0.7 f$ \\
\hline
\end{tabular}

*Values are mean of triplicate determinations \pm standard deviation.
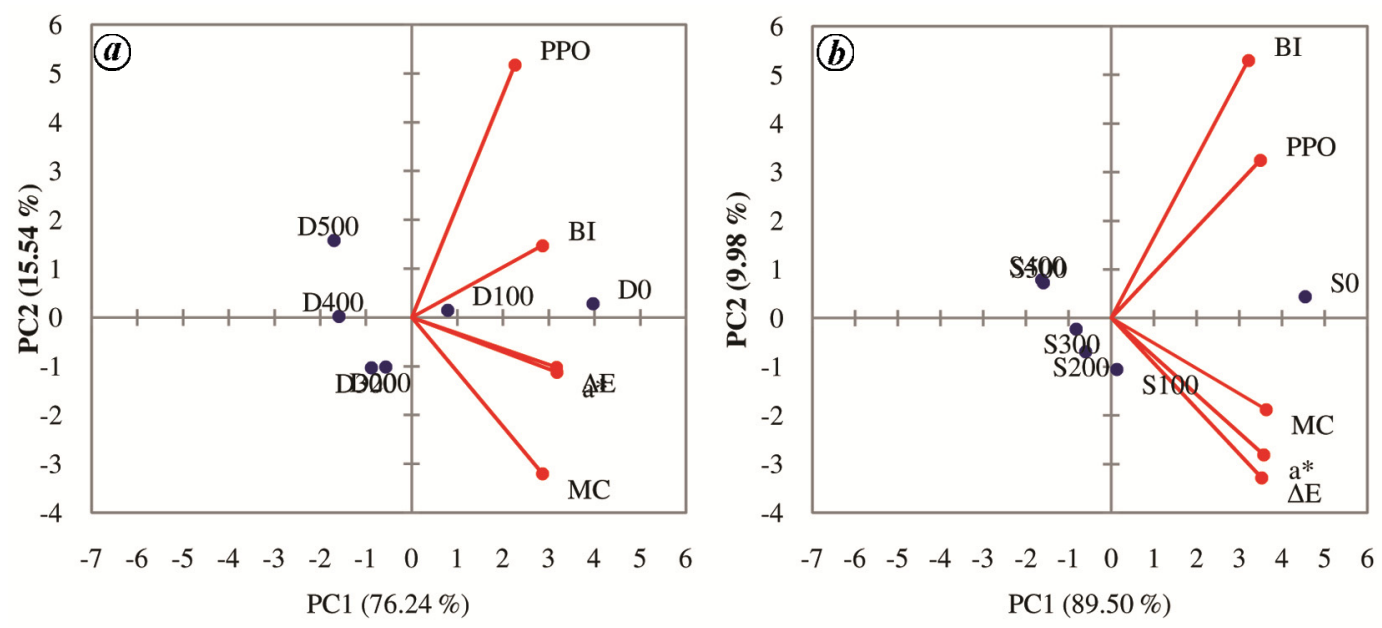

Figure 1. Principal component analysis for quality attributes of grapes subjected to (a) dipping and (b) spraying treatments.

effective PPO activity inhibitor after L-cysteine and that it acts as a direct reductant for PPO-generated orthoquinones. Importance of ascorbic acid in the inhibition of PPO activity has also been well documented ${ }^{15,25}$.

\section{Browning index}

Ascorbic acid dipping and spraying treatments showed significant $(P<0.05)$ effect on browning index of raisins (Table 5). During drying, it was observed that increase in browning index was exponential in all the samples; however, the rate of increase was highest in case of control samples (D0 and S0) and was lowest in grapes sprayed with 200 ppm of ascorbic acid (S200). On comparing all the treatments it was observed that on the last day of drying the values were $1.989,0.988,0.958,1.123$ and 1.212 for S0, S100, S200, S300, S400 and S500 samples respectively. Comparing the dipping and spraying treatments, it was observed that ascorbic acid spray samples showed lower browning index than ascorbic acid dip-treated samples. Our observations corroborate the findings in air-dried asparagus, mushrooms and apri$\operatorname{cots}^{26-29}$.

\section{Principal component analysis of raisin quality attributes}

In the present study, raisins were evaluated for moisture content, colour attributes ( $a^{*}$ and $\Delta E$ ), PPO activity and browning index. All these attributes are undesirable for a good-quality raisin. Moreover, higher values of $a^{*}, \Delta E$, PPO activity and browning index indicate the browning/darkening of raisins. Hence, their association with the samples indicates poor-quality (dark coloured) raisins. 


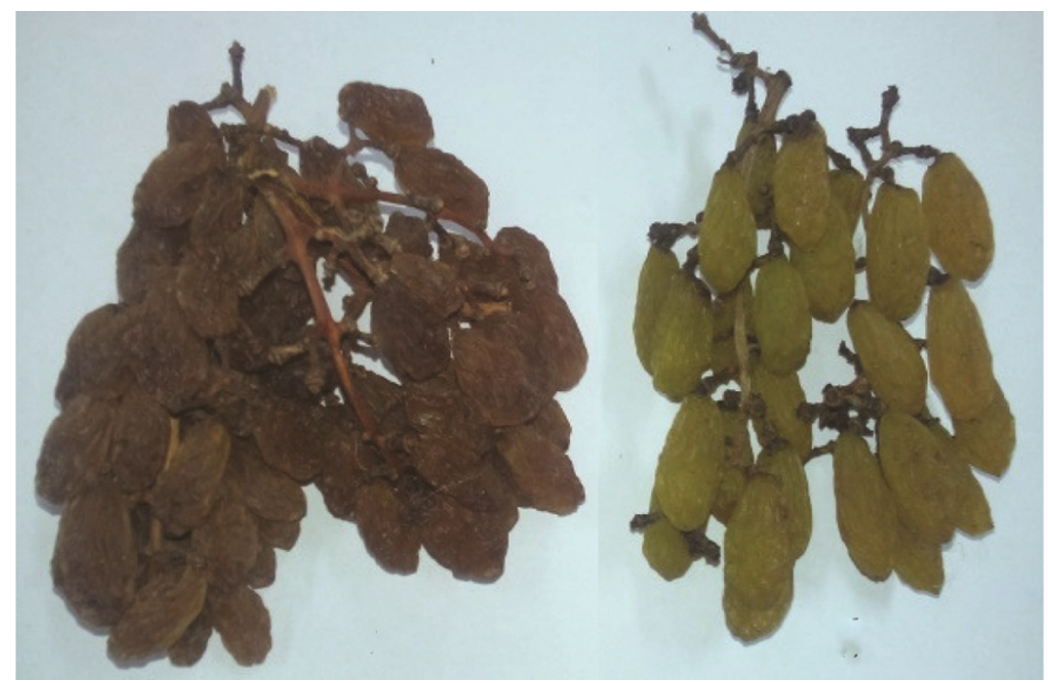

Figure 2. Raisins produced from S0 and S200 treatments.

PCA was performed for these quality attributes; Figure 1 presents the results in the form of biplots. It is evident from Figure $1 a$ that all the quality attributes show their association with dipping treatments D0 and D100 indicating that these samples have higher moisture content, brown/dark colour, higher PPO activity and higher browning index. However, samples subjected to treatments D200 to D500 did not show any association with these quality attributes, and thus indicate the retention of green colour of the raisins. Figure $1 a$ also reveals that PPO and browning index show a grouping, indicating that the increase in one attribute is associated with a simultaneous increase in the other. Similar kind of grouping was observed among $a^{*}, \Delta E$ and moisture content.

Figure $1 b$ presents results of PCA performed for quality attributes of samples subjected to spraying treatments. Results indicate that treatment S0 showed association with all the quality attributes, indicating poor quality (brown/dark colour) of the samples. However, samples subjected to spraying treatments S100 to S500 were placed at considerable distance from these quality attributes and thus indicated the production of greencoloured raisins.

Thus, PCA indicated that ascorbic acid treatments (dipping and spraying) were useful in retaining the colour and producing green-coloured raisins. However, based on all the observations (Tables 2-5 and Figures 1 and 2), treatment S200 (spray of 200 ppm ascorbic acid solution) was found optimal treatment to produce green-coloured raisins.

\section{Conclusion}

The results of the present study reveal that the application of ascorbic acid is useful in retaining the colour of raisins and improving drying rate of grapes. Application of ascorbic acid on grape bunches has been proved significant. The raisin quality was improved in ascorbic-acid treated cases compared to untreated grape berries. Different doses of ascorbic acid were recorded with reduced PPO activities during grape-drying. Spraying of ascorbic acid during drying was found more effective than ascorbic acid dip. Among different concentrations of ascorbic acid, we recommend that $200 \mathrm{ppm}$ is sufficient in controlling drying-induced browning and producing green raisins.

1. Skowron, M. J., Grzeskowiak, A. Z., Stanisz, E. and Waskiewicz, A., Potential health benefits and quality of dried fruits: goji fruits, cranberries and raisins. Food Chem., 2017, 221, 228-236.

2. Williamson, G. and Carughi, A., Polyphenol content and health benefits of raisins. Nutr. Res., 2010, 30, 511-519.

3. Ghrairia, F., Lahouar, L., El Arem, A., Brahmi, F., Ferchichi, A., Achour, L. and Said, S., Physicochemical composition of different varieties of raisins (Vitis vinifera L.) from Tunisia. Ind. Crops Prod., 2012, 43, 73-77.

4. Aguilera, J. M., Oppermann, K. and Sanch, F., Kinetics of browning of sultana grapes. J. Food Sci., 1987, 52(4), 990-993.

5. Adsule, P. G., Sharma, A. K., Banerjee, K. and Karibasappa, G. S., Raisin industry in India: adoption of good drying practices for safe raisins, Bulletin de 1'OIV 85 (n974-975-976), 2012, 209216.

6. Sharma, A. K., Rajguru, Y. R., Adsule, P. G. and Goswami, A. K., Pre-treatments of Tas-A-Ganesh grape bunches and subsequent effect on their drying. Indian J. Hortic., 2013, 70(1), 107-111.

7. Chen, X., Ren, L., Li, M., Qian, J., Fan, J. and Du, B., Effects of clove essential oil and eugenol on quality and browning control of fresh-cut lettuce. Food Chem., 2017, 214, 432-439.

8. Severini, C., Baiano, A., De Pilli, T., Romaniello, R. and Derossi, A., Prevention of enzymatic browning in sliced potatoes by blanching in boiling saline solutions. LWT-Food Sci. Technol., 2003, 36(7), 657-665.

9. Bozkurt, H. and Erkmen, O., Effects of temperature, humidity and additives on the formation of biogenic amines in sucuk during ripening and storage periods. Food Sci. Technol. Int., 2004, 10, $21-28$.

CURRENT SCIENCE, VOL. 116, NO. 6, 25 MARCH 2019 
10. Sikora, M. and Swieca, M., Effect of ascorbic acid postharvest treatment on enzymatic browning, phenolics and antioxidant capacity of stored mung bean sprouts. Food Chem., 2018, 239, 1160-1166.

11. Aguayo, E., Requejo-Jackman, C., Stanley, R. and Woolf, A., Hot water treatment in combination with calcium ascorbate dips increases bioactive compounds and helps to maintain fresh-cut apple quality. Postharvest Biol. Technol., 2015, 110, 158-165.

12. Hussain, P. R., Omeera, A., Suradkar, P. P. and Dar, M. A., Effect of combination treatment of gamma irradiation and ascorbic acid on physicochemical and microbial quality of minimally processed eggplant (Solanum melongena L.). Radiat. Phys. Chem., 2014, 103, 131-141.

13. Gil, M. I., Selma, M. V., Lopez, G., Alvez, F. and Allende, A., Fresh-cut product sanitation and wash water disinfection: problems and solutions. Int. J. Food Microbiol., 2009, 134, 37-45.

14. Fan, X. T., Sokorai, K. J., Sommers, C. H., Niemera, B. A. and Mattheis, J. P., Effects of calcium ascorbate and ionizing radiation on the survival of Listeria monocytogene and product quality of fresh-cut 'Gala' apples. J. Food Sci., 2005, 70, 352-358.

15. Soliva-Fortuny, R. C., Biosca-Biosca, M., Grigelmo-Miguel, N. and Martiin-Belloso, O., Browning, polyphenol oxidase activity and headspace gas composition during storage of minimally processed pears using modified atmosphere packaging. J. Agric. Food Chem., 2002, 82, 1490-1496.

16. Sharma, A. K., Ramteke, S. D., Lahoti, M. and Adsule, P. G., Effect of ascorbic acid and sodium metabisulphite application on Thompson seedless grape bunches during drying. In Proceeding of the 5th Indian Horticulture Congress, Ludhiana, 2012.

17. Venkatram, A., Padmavathamma, A. S., Vijaya, D., Siva Sankar, A., Manorama, K. and Srinivas Rao, B., Studies on various concentrations of antioxidants with alkaline emulsion of ethyl oleate as pre-treatment on rate of drying, yield and colour of raisins prepared from seedless grape (Vitis vinifera L.). Int. J. Curr. Microbiol. Appl. Sci., 2017, 6(9), 2785-2793; doi.org/10.20546/ ijcmas.2017.609.343.

18. AACC International, Approved Methods of the American Association of Cereal Chemists, Methods 14-50 and 44-15A, The Association, St Paul, MN, USA, 2000, 10th edn.

19. Francis, F. J. and Clydesdale, F. M., Food Colorimetry: Theory and Applications, Van Nostrand Reinhold/AVI, New York, USA, 1975.
20. Nath, P., Kale, S. J., Chauhan, O. P. and Gupta, R. K., High pressure processing induced changes in bioactive compounds, antioxidant activity, microbial safety and colour attributes of coriander paste. Agric. Res., 2016, 5(2), 182-192.

21. Meydav, S., Saguy, I. and Kopelman, I. J., Browning determination in citrus products. J. Agric. Food Chem., 1977, 25, 602-604.

22. Grncarevic, M. and Lewis, W. J., Drying of grapes in Australia. Food Technol. Aust., 1976, 28, 66-67; 69-71; 76.

23. Zheng, Y., Shi, J. and Pan, Z., Biochemical characteristics and thermal inhibition kinetics of polyphenol oxidase extracted from Thompson seedless grape. Eur. Food Res. Technol., 2012, 234(4), 607-616.

24. Yaar, H., Some biochemical properties of polyphenol oxidase from celery. Prep. Biochem. Biotechnol., 2004, 34, 387-397.

25. Unal, M. U. S. and Ener, A., Determination of some biochemical properties of polyphenol oxidase from Emir grape (Vitis vinifera L. cv. Emir). J. Sci. Food Agric., 2006; doi:10.1002/jsfa.2627.

26. Chen, Y. and Martynenko, A., Computer vision for real-time measurements of shrinkage and colour changes in blueberry convective drying. Drying Technol., 2013, 31, 1114-1123; doi: 10.1080/07373937.2013.775587.

27. Nindo, C. I., Sun, T., Wang, S. W., Tang, J. and Powers, J. R., Evaluation of drying technologies for retention of physical quality and antioxidants in asparagus. LWT-Food Sci. Technol., 2003, 36, 507-516.

28. Argyropoulos, D., Heindl, A. and Muller, J., Assessment of convection, hot-air combined with microwave-vacuum and freezedrying methods for mushrooms with regard to product quality. Int. J. Food. Sci. Technol., 2011, 46(2), 333-342.

29. Karabulut, I., Topcu, A., Duran, A., Turan, S. and Ozturkc, B., Effect of hot air drying and sun drying on colour values and $\beta$ carotene content of apricot (Prunus armenica L.). LWT-Food Sci. Technol., 2007, 40(5), 753-758.

ACKNOWLEDGEMENT. We thank ICAR-Central Institute of PostHarvest Engineering and Technology, Abohar for financial support and providing the necessary facilities.

Received 7 March 2018; accepted 5 September 2018

doi: $10.18520 / \mathrm{cs} / \mathrm{v} 116 / \mathrm{i6} / 943-951$ 